\title{
Author Correction: A corridor of exposed ice-rich bedrock across Titan's tropical region
}

Caitlin A. Griffith (D), Paulo F. Penteado, Jake D. Turner (D), Catherine D. Neish, Giuseppe Mitri (D), Nicholas J. Montiel, Ashley Schoenfeld and Rosaly M. C. Lopes iD

Correction to: Nature Astronomy https://doi.org/10.1038/s41550-019-0756-5, published online 29 April 2019.

In the version of this Article originally published, the author Rosaly Lopes was mistakenly affiliated with Northern Arizona University. Her affiliation has now been corrected to: Jet Propulsion Laboratory, California Institute of Technology, Pasadena, CA, USA. 